\title{
CORRECTION
}

\section{Hot bodies; Cold War: the \\ forgotten history of breast thermography}

A Humanities article published on Apr. 18, $2017,{ }^{1}$ incorrectly stated that Ray Newton Lawson was born in 1912. In fact, he was born in 1914.

- Cite as: CMAJ 2017 June 19;189:E842. doi: 10.1503/cmaj.170609

\section{Reference}

1. Fraser J. Hot bodies; Cold War: the forgotten history of breast thermography. CMAJ 2017;189: E573-5. 